\title{
The Polymorphism rs2293855 MTMR9 Gene and Genetic Score Are Associated With Higher Atherogenic Risk in Brazilian Schoolchildren
}

\section{Mariane Silva}

Universidade Federal de Vicosa https://orcid.org/0000-0002-6518-6534

Cristina Maria Mendes Resende

Universidade Federal de Pernambuco

Maíra Barros Louro

Universidade Federal de Minas Gerais

Sarah Aparecida Vieira Ribeiro

Universidade Federal de Vicosa

Sylvia do Carmo Castro Franceschini

Universidade Federal de Vicosa

Jorge Gustavo Velásquez-Meléndez

Universidade Federal de Vicosa

Jacqueline Isaura Alvarez Leite

Universidade Federal de Minas Gerais

Danielle Fernandes Durso

University of Massachusetts Medical School

Juliana Farias de Novaes ( $\nabla$ jnovaes@ufv.br)

Universidade Federal de Vicosa

\section{Research Article}

Keywords: children, single nucleotide polymorphism, dyslipidemia, cardiovascular disease

Posted Date: December 10th, 2021

DOI: https://doi.org/10.21203/rs.3.rs-1118470/v1

License: (c) (i) This work is licensed under a Creative Commons Attribution 4.0 International License.

Read Full License 
The polymorphism rs2293855 MTMR9 gene and genetic score are associated with higher atherogenic

4 Mariane Alves Silva ${ }^{1 *}$, Cristina Maria Mendes Resende ${ }^{2 *}$, Maíra Barros Louro ${ }^{3}$, Sarah Aparecida Vieira

5 Ribeiro ${ }^{1}$, Sylvia do Carmo Castro Franceschini ${ }^{1}$, Jorge Gustavo Velásquez Meléndez ${ }^{3}$, Jacqueline Isaura

6 Alvarez Leite ${ }^{3}$, Danielle Fernandes Durso ${ }^{4}$, Juliana Farias de Novaes ${ }^{1}$

8 Affiliations:

$9 \quad{ }^{1}$ Department of Nutrition and Health, Universidade Federal de Viçosa (UFV), Av. P.H. Rolfs s/n, Campus 10 Universitário, CEP 36570-900, Viçosa - Minas Gerais, Brazil.

$11{ }^{2}$ Postgraduate Program in Hebiatrics, University of Pernambuco, Av. Agamenon Magalhães, Santo Amaro, 12 Zip Code: 50100-10, Recife - Pernambuco, Brazil

$13{ }^{3}$ Department maternal and child care, Nursing school, Universidade Federal de Minas Gerais (UFMG), Av.

14 Alfredo Balena, 190, Santa Efigênia, CEP 30130-100, Belo Horizonte - Minas Gerais, Brazil.

$15{ }^{4}$ Department of Neurology, Wellstone Program, University of Massachusetts Medical School, Massachusetts, 16 USA.

Juliana Farias de Novaes. Department of Nutrition and Health, Universidade Federal de Viçosa (UFV), Av.

22 P.H. Rolfs s/n, Campus Universitário, CEP 36570-900, Viçosa - Minas Gerais, Brazil. E-mail: jnovaes @ ufv.br 
Purpose: Evaluate the associations of FTO (rs9939609), MC4R (rs17782313), MTMR9 (rs2293855), and

44 the genetic score with atherogenic risk in Brazilian children.

45 Methods: This is a cross-sectional study conducted with 544 children aged 4 to 9 years old. We obtained 46 sociodemographic and lifestyle data by questionnaires, and biological sample (DNA) through oral swab.

47 The single nucleotide polymorphisms (SNP) FTO (rs9939609), MC4R (rs17782313), and MTMR9 48 (rs2293855) were identified by the system taqman SNP genotyping and evaluated the obesity-related 49 genetic risk score. Blood samples were collected for the lipid profile analysis (serum total cholesterol, HDL50 c, LDL-c, triglycerides). The atherogenic indexes (Castelli I and II indexes, atherogenic coefficient - AC, 51 lipoprotein combination index - LCI and plasma atherogenic index - AIP) were calculated. We compared 52 the distributions of outcomes (lipid profile and atherogenic indexes) by genotype categories using 53 multivariable linear regression.

54 Results: Children with AG/AA genotypes in the polymorphism MTMR9 (rs2293855), had lower HDL-c 55 level and higher TC/HDL-c, LDL-c/HDL-c ratios, and AC. Those with one or more polymorphisms (FTO 56 rs9939609, MC4R rs17782313, and MTMR9 rs2293855) in the genetic risk score had lower HDL-c and 57 higher TC/HDL-c, AC, LCI, and AIP.

58 Conclusion: The risk allele (AG/AA) of the MTMR9 (rs2293855) and the higher obesity-related genetic 59 risk score were positively associated with higher atherogenic risk in Brazilian children.

60

61 Key-words: children, single nucleotide polymorphism, dyslipidemia, cardiovascular disease. 
Cardiovascular diseases (CVD) are responsible annually for the death of 17.9 million people in

83 the world [1], and the dyslipidemia is an important risk factor for its occurrence [2], that is characterized

84 by the increase in the concentration of lipids or lipoproteins in the blood. The dyslipidemia can be influenced by environmental and genetic factors [3], being the latter responsible for about $40 \%$ of this occurrence [4].

The association of increased levels of total cholesterol (TC), low-density lipoprotein cholesterol (LDL-c), triglycerides (TG), and low values of high-density lipoprotein cholesterol (HDL-c) are associated with the risk for CVD in children [5,6,7]. However, it is necessary to evaluate atherogenic indexes, such as the LDL/HDL and TC/HDL ratios, atherogenic plasma index (AIP), atherogenic coefficient (AC) and the lipoprotein combined index (LCI), once that they have a greater predictive capacity for cardiovascular risk than isolated traditional markers $[8,9]$.

The knowledge of the gene-disease relationship is of great importance, once it allows early action in the prevention and treatment of pathologies, and also, because we can present different responses when the same intervention occurs [10]. In adults, the relationship between the genes Fat Mass and Obesity Associated (FTO) rs9939609, Myotubularin-related protein 9 (MTMR9) rs2293855 [11] and Melanocortin4 receptor (MC4R) rs2229616 [12] and dyslipidemia is already presented. Others studies with adults identified that carriers of the FTO rs9939609 and MC4R rs12970134 A-allele showed changes in the lipid profile, with a decrease of HDL-c, and increase of TG, TC and AIP [13,14]. In children, no relationship was found between FTO rs993960 and the alterations in the lipid profile [15]. We did not find studies evaluating the association of polymorphisms in the MC4R and MTMR9 genes with dyslipidemia in childhood.

Since childhood dyslipidemia is associated with cardiovascular diseases in adulthood, and early diagnosis and preventive actions can reduce heart diseases' mortality in adults [16], we highlight the importance to study of the gene-dyslipidemia relationship in young ages. Considering the absence of studies, mainly in relation to the MC4R and MTMR9 genes, that evaluated the occurrence of genetic

107 polymorphisms related with lipid markers and atherogenic indexes in childhood [11,17], the objective of

108 this study was to evaluate the association of the FTO (rs9939609), MC4R (rs17782313), MTMR9

109 (rs2293855) polymorphisms and the obesity-related genetic risk score with atherogenic risk in Brazilian

110 children. We hypothesize is that these alleles are associated with higher atherogenic risk.

\section{MATERIALS AND METHODS}

\section{Participants and study design}

114 This is a cross-sectional study conducted with 544 children aged from 4 to 9 years old, in the city 115 of Viçosa, Minas Gerais, Brazil, as part of the Schoolchildren Health Assessment Survey (PASE, in 116 portuguese) and the Lactation Support Program (PROLAC, in portuguese) accomplished in 2015 and 1172016.

118 The sample size calculation and the sampling process of PASE [18,19] and PROLAC [20] have 119 been described previously. Figure 1 presents the sampling process of the children participating in this study. 
120 All the children were reevaluated in 2018, with measurements of weight and height, body mass index calculation, and the genetic material collected through an oral swab. of the TC in the group without the risk allele of the MTMR9 rs2293855 (GG/AG) $(155.7 \pm 26.2)$ and with the risk allele (AA) $(158.2 \pm 33.3)$ by the OpenEpi software. The statistical significance level was $5 \%$, and the sample size had power $\geq 80 \%$. The calculation of the sample size was performed for all polymorphisms and the MTMR9 rs2293855 was the one with the lowest statistical power.

This study was developed according to the guidelines established in the Declaration of Helsinki and approved by the Human Research Ethics Committee of the Federal University of Viçosa (UFV, in

133 Portuguese) (protocols numbers 663.171/2014, 892476/2014 and 2.832.590/2018). All parents and children 134 were informed about the study's purpose and all guardians of the children signed the Informed Consent 135 Form.

\section{Laboratory Methods}

All evaluations were done at the Laboratory of Clinical Analysis in UFV. Blood samples were collected intravenously after 12 hours of fasting.

The lipid profile (TG, TC, LDL-c, and HDL-c) was quantified by automatic equipment (BioSystems 200 Mindray ${ }^{\circledR}$ model, Nanchan, China) according to the recommendations of the kit manufacturer (Bioclin ${ }^{\circledR}$, Belo Horizonte, MG, Brazil). Children with at least one of the following altered 143 lipids were classified with dyslipidemia [21]: TC $\geq 170 \mathrm{mg} / \mathrm{dL}$, HDL-c $<45 \mathrm{mg} / \mathrm{dL}$, LDL-c $\geq 110 \mathrm{mg} / \mathrm{dL}$, $144 \mathrm{TG} \geq 75 \mathrm{mg} / \mathrm{dL}$. index risk II (LDL-c/HDL-c), atherogenic index of plasma (AIP), atherogenic coefficient (AC), and 
147 lipoprotein combine index (LCI). The non-HDL-c was estimated by the equation: (TC - HDL-c). AIP was

148 defined as the base 10 logarithms of the TG/HDL-c ratio. AC and LCI were defined as non-HDL-c/HDL-

$149 \mathrm{c}$ and (TC x TG x LDL)/HDL-c ratios, respectively [22-24].

Single Nucleotide Polymorphisms Genotyping

In the collection of buccal cells was performed with circular movements, 30 times on each side on the inner face of both cheeks with a sterilized cytological brush. The brushes were placed in absolute ethanol and storage on $4^{\circ} \mathrm{C}$ refrigerator until the moment of DNA extraction. Genomic DNA was extracted from buccal epithelial cells following a modified protocol of Miller, Dykes, Polesky (1988) [25] and were kept at -20 degress. The concentration and purity of the DNA was determined by spectrophotometry using NanoDrop 2000c. DNA concentration was evaluated at $260 \mathrm{~nm}$ and the ratio of readings at $260 \mathrm{~nm}$ and 280 $\mathrm{nm}$ was used to estimate the DNA purity.

The chosen SNPs were genotyped using the real-time PCR TaqMan assay utilizing two differentially fluorescently labeled probes that permitted the detection of both alleles in a single reaction (Applied Biosystems INC, Foster City, CA, USA) [26]. The PCR primers and Taqman probes had been previously developed at Applied Biosystems for each SNP studied. Assays were performed on an ABI 7900

163 HT Fast PCR Real Time System (Applied Biosystems, Foster City, CA), and the genotype assignments were conducted using the TaqMan ${ }^{\mathrm{TM}}$ Genotyper Software, in a 384-well format and using manufacturer's instructions. The commercial classifications of the TaqManTM SNP Genotyping methodology test used by

166 ABI specific for the study of the FTO site is C__30090620_10, locus MC4R is C_32667060_10 and locus MTMR9 is C__16185295_10. The Taq-Man ${ }^{\mathrm{TM}}$ SNP Genotyping methodology was based on using a predesigned assay and validated by the company Applied Biosystems (ABI).

The obesity-related genetic risk score was calculated using the genotype information according to the allelic composition of the three SNPs studied [27]. The genotypes were coded zero, 1, 2 and 3, creating a score, adding the numbers of genotypes of each study participant. The children received a score "zero" when presented no risk allele (TT, TT, GG), "1" when presented one risk allele in the FTO rs9939609, MC4R rs17782313 or MTMR9 rs2293855 gene, " 2 " when presented the polymorphism of two genes, and "3" when presented all polymorphisms. After, the children were divided into two groups, those that did not have any polymorphism and those that had one or more genetic polymorphisms.

A semi-structured questionnaire was applied, pre-coded, and pre-tested in a pilot study by the researchers, containing variables such as sex and age of the children, maternal education, and household's per capita income.

181 Sedentary behavior was assessed using screen time, including television, video game, computer, cell phone, and tablets. According to the American Academy of Pediatrics (2013) [28], the child who had a screen time higher than 2 hours per day was classified as sedentary. 

electronic digital scale (Tanita ${ }^{\circledR}$, model BC 553, Arlington Heights, IL, USA), with a capacity of $150 \mathrm{~kg}$ and a sensitivity of $50 \mathrm{~g}$. Children were weighed without shoes and wearing light clothes. Height was measured using a vertical anthropometer (Alturexata ${ }^{\circledR}$, Belo Horizonte, MG, Brazil), divided into centimeters and subdivided into millimeters, according to the standards recommended by Jelliffe (1968) [29].

Body composition was evaluated by Dual Energy X-ray Absorptiometry (DXA). The examination was carried out at the Health Division of the Federal University of Viçosa. This equipment is considered a reference method for assessing body composition and, due to the low radiation level, it does not pose any health risk [30]. During the scanning, the child remained in a supine position, and the protocol was

Data analyses established for the child to be in light clothing, without earrings, bracelets, or any metal adornment.

Exposures. Genotypes polymorphisms (FTO rs9939609, MC4R rs17782313, MTMR9 rs2293855, and genetic risk score) as categorical variables.

Outcomes. Lipid markers (TC, LDL-c, HDL-c, TG, and non-HDL-c) and atherogenic indexes (Castelli risk indexes I and II, AC, LCI, and AIP) as continuous variables.

\section{3} fat, screen time, the household's per capita income, maternal education, and total energy intake. Heightand BMI-for-age Z-score were calculated according to the sex- and age-specific reference for children and adolescents [31].

Statistical analyses. The normality of the variables was assessed by the Kolmogorov-Smirnov test. We evaluated the distributions of outcomes (lipid profile and atherogenic indexes) using mean \pm standard deviation (SD) according to sociodemographic, anthropometric, body composition, and lifestyle characteristics. Then, we compared the distributions of outcomes (lipid profile and atherogenic indexes) by genotype categories (exposure), using mean differences and 95\% confidence intervals (CI) from unadjusted and multivariable linear regression models adjusted by sex, age, screen time, per capita income, maternal education, body fat, and total energy intake. The adjustment variables were selected based on the literature review, and robust estimates of the variance were specified in all models, which are consistent to heteroscedasticity and normality [32]. Analyses were carried out in the Stata ${ }^{\circledR}$ version 14 (StataCorp LP, College Station, TX, USA). The significance level was $5 \%$ for all hypothesis tests.

A total of 544 children were evaluated in this study, the mean \pm SD age of participants was $7.2 \pm$ genotypic frequencies of the FTO (rs9939609), MC4R (rs17782313), MTMR9 (rs2293855) on the studied populations.

RESULTS 1.6 years old; $51.3 \%$ were girls, and $55.5 \%$ presented dyslipidemia. We observed that $32.4 \%$ did not show the risk allele (TT), $49.6 \%$ had a risk allele (AT) and $18 \%$ presented two risk alleles (AA) of the FTO polymorphism. In relation to the $M C 4 R 61.5 \%$ did not show the risk allele (TT), 33.8\% had a risk allele 
(TC) and $4.7 \%$ presented two risk alleles (CC) of the $M C 4 R$ polymorphism. $45 \%$ of children did not show the risk allele (GG), $45.1 \%$ had a risk allele (AG) and $9.9 \%$ presented two risk alleles (AA) of the MTMR9 polymorphism. Children with over one or two polymorphisms in the obesity-related genetic risk score were $28.5 \%$ and $2.2 \%$, respectively. Genotypic proportions were in Hardy-Weinberg equilibrium.

Height-for-age Z-score was negatively associated with LDL-c and LDL-c/HDL-c. BMI-for-age Zscore and body fat were negatively associated with HDL-c, and positively associated with TG, LCI, and AIP. In addition, BMI-for-age was positively associated with TC/HDL-c and AC. Per capita income and maternal education were positively associated with LDL-c, TG, LCI, and AIP. Moreover, maternal education was positively associated with TC, non-HDL-c, TC/HDL-c, LDL-c/HDL-c, and AC, (Table 1).

We did not find associations of the risk alleles FTO rs9939609 and MC4R rs17782313 with the atherogenic risk (Tables 2 and 3).

After the adjustment for potential confounders, the risk alleles of the MTMR9 rs2293855 was positively associated with lipid markers and atherogenic risk. Individuals with AG/AA genotypes in the MTMR9 rs2293855 were related to -1.75 (95\% CI: -3.12, -0.38) units lower of HDL-c; and to 0.15 (95\% CI: 0.01, 0.29), 0.13 (95\% CI: 0.01, 0.25), and 0.15 (95\% CI: 0.01, 0.29) unit higher of TC/HDL-c, LDLc/HDL-c and AC, respectively, in comparison with children without polymorphism (Table 4).

In the same way, after adjustment, the genetic risk score was negatively associated with HDL-c and positively associated with the TC/HDL-c, AC, LCI and AIP. Children who had one or more polymorphisms were related to -2.11 (95\% CI: $-4.08,-0.14$ ) units lower of HDL-c; and to 0.16 (95\% CI: 0.02, 0.31), 0.16 (95\% CI: 0.02, 0.31), 4.36 (95\% CI: 0.30, 8.36), 0.04 (95\% CI: 0.004, 0.08) units higher of TC/HDL-c, AC, LCI, and AIP, respectively, in comparison with children that presented null obesity-

\section{DISCUSSION}

In this cross-sectional study with Brazilian children, we confirmed the hypothesis that the risk allele of the MTMR9 rs2293855 polymorphism and the obesity-related genetic risk score were positively associated with higher atherogenic risk. Despite the prevalence of the FTO rs9939609 and MC4R rs 17782313 polymorphisms in this study being similar to other studies [33-36], we did not find associations of these risk alleles with the atherogenic risk in children. It is also noteworthy the high prevalence of dyslipidemia among children in this study.

To our knowledge this is first study identify a direct relationship between the MTMR9 rs 2293855 polymorphism with the lipid markers and atherogenic indexes (HDL-c, TC/HDL-c, LDL-c/HDL-c, and AC) in schoolchildren. This association has been demonstrated previously, but in a study with Japanese adults, that found positive association between MTMR9 rs2293855 polymorphism and metabolic syndrome, including alterations in markers of dyslipidemia, hypertension and fasting glucose [11].

Although the mechanisms of action of the $M T M R 9$ gene on lipid profile markers are not clear, it is believed that this association is complex and mediated by changes in adiposity and blood glucose. The MTMR9 gene affects glucose transport through the dephosphorylation of phosphatidylinositol 3-phosphate (PtdIns3P) [17,37]. Individuals with MTMR9 rs2293855 polymorphism presented higher fasting glucose, glucose intolerance, reduced insulin sensitivity and increased risk of prediabetes [37]. Still, Yanagiya et al. 
(2007) [17] when evaluating an association of the MTMR9 rs2293855 polymorphism with obesity, identified an association between genetic polymorphism and higher BMI values. It is known that excess adiposity, especially in the visceral region, is associated with insulin resistance and this hormone has an antilipolytic effect. Therefore, changes in insulin performance can increase triglyceride hydrolysis, with consequent excessive release of free fatty acids into the circulation and change in lipid profile markers $[38,39]$. It is also noteworthy that some key enzymes involved in HDL metabolism, such as cholesterol ester transfer protein (CETP), lecithin/cholesterol acyltransferase (LCAT), liver lipase (HL) and protein phospholipid transfer protein (PLTP) are altered in people with obesity that has insulin resistance [40].

It is noteworthy that, like any gene expressed in the hypothalamus, MTMR9 plays a role in the regulation of hypothalamic peptides, regulating appetite and influencing food preferences [17]. It is speculated that individuals with the polymorphism in the MTMR9 gene would have a greater preference for fatty foods, thus contributing to the occurrence of dyslipidemia.

We did not find associations of FTO rs9939609 and MC4R rs17782313 polymorphisms with dyslipidemia, which corroborates with other studies [41-43]. It is known that the FTO and MC4R gene are expressed in different ways in the individual, depending on their age. The same variant associated with obesity and insulin resistance in adults did not show significant differences among children [44-46], that is in accordance with our sample.

Our findings showed that the obesity-related genetic risk score was positively associated with the lipid markers and atherogenic indexes (HDL-c, TC/HDL-c, AC, LCI, AIP). A review study identified that genetic risk scores have been a way of aggregating multiple sets of results into a single genetic predictor for cardiovascular diseases [47]. It is important to consider the interaction of genes in our body [48], and studies have identified a higher predictive value of the genetic risk score for cardiovascular risk when compared to a single genetic variant worked in isolation $[49,50]$.

Several studies have shown the relationship between the FTO rs9939609 [51,52] and MTMR9 rs2293855 [17] polymorphisms with weight excess in adults, and between MC4R rs17782313 polymorphisms with obesity in children [53]. Despite knowing that adipose tissue plays a central role in maintaining lipid homeostasis [54], we could evidence the relationship of MTMR9 rs2293855 polymorphism and the genetic risk score with higher atherogenic risk in schoolchildren, even after adjusting for body fat.

Although the power of this study is higher than $80 \%$, it presents a limitation that our data was not representative of the city of Viçosa, nor of Brazilian population, so the results generalization should be avoided. However, several strengths need to be highlighted. To our knowledge, this is the first study to evaluate the association of the MTMR9 rs2293855 polymorphism and genetic risk score with the lipid markers and non-traditional atherogenic indexes which, these last, according to the literature, have a higher predictive value for cardiovascular risk [8].

We conclude that the risk allele of the MTMR9 rs2293855 and the obesity-related genetic risk score were positively associated with higher atherogenic risk in Brazilian children. More attention should be given to evaluating risk allele to better understand the relation between genotype and alterations of the 
1. World Health Organization. Noncommunicable Diseases. (Accessed on 18 May 2020 at https://www.who.int/data/gho/data/themes/noncommunicable-diseases).

2. Pöss J, Custodis F, Werner C, Weingärtner O, Böhm M, Laufs U. Cardiovascular disease and dyslipidemia: beyond LDL. Curr Pharm Des 2011; 17: 861-870.

3. Brasil. Atualização da Diretriz Brasileira de Dislipidemias e Prevenção da Aterosclerose - 2017. Soc Bras Cardiol 2017; 109:1-90.

4. Weiss LA, Pan L, Abney M, Ober C. The sex-specific genetic architecture of quantitative traits in humans. Nat Genet 2006;38(2):218-22.

5. Expert panel on integrated guidelines for cardiovascular health and risk reduction in children and adolescents: summary report. Pediatrics 2011; 128 Suppl 5: S213-56.

6. Viitasalo A, Schnurr TM, Pitkänen N, Hollensted M, Nielsen TRH, Pahkala K. Abdominal adiposity and cardiometabolic risk factors in children and adolescents: a Mendelian randomization analysis. Am J Clin Nutr 2019; 00: 1-9.

7. Varda NM, Medved M, Ojsteršek L. The associations between some biological markers, obesity, and cardiovascular risk in Slovenian children and adolescentes. BMC Pediatrics 2020; $20: 81$.

8. Shen S, Lu Y, Qi H, Li F, Shen Z, Wu L, et al. Association between ideal cardiovascular health and the atherogenic index of plasma. Medicine 2016; 95(24).

9. Guo Q, Zhou S, Feng X, Yang J, Qiao J, Zhao Y, et al. The sensibility of the new blood lipid indicator atherogenic index of plasma (AIP) in menopausal women with coronary artery disease. Lipids Health Dis 2020; 19:27.

10. Steemburgo T, Azevedo MJ, Gross JL, Milagro FI, Campion J, Martínzez JÁ, et al. The rs9939609 polymorphism in the FTO gene is associated with fat and fiber intakes in patients with type 2 diabetes. J Nutrigenet Nutrigenomics 2013; 6(2): 97-106.

11. Hotta K, Kitamoto T, Kitamoto A, Mizusawa S, Matsuo T, Nakata Y, et al. Association of variations in the FTO, SCG3 and MTMR9 genes with metabolic syndrome in a Japanese population. J Hum Genet 2011; 56(9): 647-651. 
12. Kang SH, Han HR, Lee JI, Karmacharya R, Jeon HJ, Roh S. Effects of LEP, LEPR, ADIPOQ, MC4R and FTO polymorphisms on dyslipidemia in Korean patients with schizophrenia who are taking clozapine. Psychiatry Res 2015; 228(1): 177-8.

13. Doney ASF, Dannfald J, Kimber CH, Donnelly LA, Pearson E, Morris AD, et al. The FTO gene is associated with an atherogenic lipid profile and myocardial infarction in patients with type 2 diabetes: A Genetics of Diabetes Audit and Research Study in Tayside Scotland (Go-DARTS) Study. Circ Cardiovasc Genet 2009, 2, 255-259.

14. Perez-Martinez P, Garcia-Rios A, Delgado-Lista J, Delgado-Casado N, Malagon MM, Marin C, et al. A variant near the melanocortin-4 receptor gene regulates postprandial lipid metabolism in a healthy Caucasian population. Br J Nutr 2011, 106, 468-471.

15. Gesteiro E, Sánchez-Muniz FJ, Ortega-Azorín C, Guillén M, Corella D, Bastida S. Maternal and neonatal FTO rs9939609 polymorphism affect insulin sensitivity markers and lipoprotein profile at birth in appropriate-for-gestational-age term neonates. J Physiol Biochem 2016.

\section{Pires A, Sena C, Seiça R. Dyslipidemia and cardiovascular changes in children. Curr Opin Cardiol} 2016; 31(1): 95-100.

\section{Yanagiya T, Tanabe A, Lida A, Saito S, Sekine A, Takahashi A, et al. Association of single-} nucleotide polymorphisms in MTMR9 gene with obesity. Hum Mol Genet 2007; 16, 3017-3026.

18. Filgueiras MS, Vieira AS, Fonseca PCA, Pereira PF, Ribeiro AQ, Priore SE. et al. Waist circumference, waist-to-height ratio and conicity index to evaluate android fat excess in Brazilian children. Public Health Nutr 2019; 22(1): 140-146.

19. Suhett LG, Silveira BKS, Filgueiras MS, Peluzio MCG, Hermsdorff HHM, Novaes JF. Inverse association of calcium intake with abdominal adiposity and C-reactive protein in Brazilian children. Public Health Nutr 2018: 1-9.

20. Vieira-Ribeiro SA, Andreoli CS, Fonseca PCA, Hermsdorff HHM, Pereira PF, Ribeiro AQ, et al. Dietary patterns and body adiposity in children in Brazil: a cross-sectional study. Public Health 2019: 140-147.

21. Faludi AA, Izar MC, Saraiva JF, Chacra AP, Bianco HT, Afiune-Neto A, et al. Atualização da diretriz brasileira de dislipidemias e prevenção da aterosclerose-2017. Arq Bras Cardiol 2017; 109(2): 1-76. 
22. Wu TT, Gao Y, Zheng YY, Ma YT, Xie X. Atherogenic index of plasma (AIP): a novel predictive indicator for the coronary artery disease in postmenopausal women. Lipids Health Dis 2018; 17(1): 197.

23. Millán J, Pintó X, Muñoz A, Zúñiga M, Rubiés-Prat J, Pallardo LF, et al. Lipoprotein ratios: physiological significance and clinical usefulness in cardiovascular prevention. Vascular Health Risk Manag 2009; 5: 757.

24. Dobiášová M, Frohlich J. The plasma parameter log (TG/HDL-C) as an atherogenic index: correlation with lipoprotein particle size and esterification rate inapob-lipoprotein-depleted plasma (FERHDL). Clin Biochem 2001; 34(7), p.583-8, 2001.

25. Miller SA, Dykes DD, Polesky HF. A simple salting out procedure for extracting DNA from human nucleated cells. Nucleic Acids Res 1988; 16(3): 1215.

28. American Academy of Pediatrics. Council on Communications and Media Children, adolescents, and the media. Pediatrics 2013; 132(5): 958-961.

26. Durso DF, Bydlowski SP, Hutz MH, Suarez-Kurtz G, Magalhães TR, Pena SD. Association of genetic variants with self-assessed color categories in Brazilians. PLoS One 2014;9(1), e83926.

27. Kong X, Xing X, Zhang X, Hong J, Yang W. Sexual Dimorphism of a Genetic Risk Score for Obesity and Related Traits among Chinese Patients with Type 2 Diabetes. Obesity Facts 2019; 12: 328-343.

419 

variants on obesity, inflammation and cardiovascular disease risk biomarkers in Spanish children: a case-control multicentre study. BMC Medical Genet 2013; 14.

34. Silva CF, Zandoná MR, Vitolo MC, Campagnolo PDB, Rotta LN, Almeida S, et al. Association between a frequent variant of the FTO gene and anthropometric phenotypes in Brazilian children. BMC Medical Genet 2013.

35. Song JY, Song QY, Wang S, Wang HJ. Physical Activity and Sedentary Behaviors Modify the Association between Melanocortin 4 Receptor Gene Variant and Obesity in Chinese Children and Adolescents. PLoS One 2017, 1-11.

36. Ulloa N, Villagran M, Riffo B, Gleisner A, Petermann-Rocha F, Mardones L, et al. Association between FTO gene rs9939609 and adiposity markers in Chilean children. Rev Chil Pediatr 2020; 91(3): 371-378.

37. Tang L, Tong Y, Cao H, Xie S, Yang Q, Zhang F, et al. The MTMR9 rs2293855 polymorphism is associated with glucose tolerance, insulin secretion, insulin sensitivity and increased risk of prediabetes. Gene 2014; 546: 150-155.

\section{Zhang T, Chen J, Tang X, Luo Q, Xu D, Yu B. Interaction between adipocytes and high-density} lipoprotein:new insights into the mechanism of obesity-induced dyslipidemia and atherosclerosis. Lipids in Health Dis 2019; 18:223.

39. Lechner K, McKenzie AL, Krankel N, Schacky CV, Worm N, Nixdorff U, et al. High-Risk Atherosclerosis and Metabolic Phenotype: The Roles of Ectopic Adiposity, Atherogenic Dyslipidemia, and Inflammation. Metab Syndr Relat Disord 2020; 18:4.

40. Rashid SGJ. Effect of obesity on high-density lipoprotein metabolism. Obesity 2007; 15: 287588.

41. Müller TD, Hinney A, Scherag A, Nguyen TT, Schreiner F, Schäfer H, Hebebrand J, Roth CL, Reinehr T. 'Fat mass and obesity associated' gene (FTO): no significant association of variant rs9939609 with weight loss in a lifestyle intervention and lipid metabolism markers in German obese children and adolescents. BMC Med Genet 2008;

42. Gesteiro E, Sánchez-Muniz FJ, Ortega-Azorín C, Guillén M, Corella D, Bastida S. Maternal and neonatal FTO rs9939609 polymorphism affect insulin sensitivity markers and lipoprotein profile at birth in appropriate-for-gestational-age term neonates. J Physiol Biochem 2016. 

between the components of metabolic syndrome and the polymorphisms in the peroxisome proliferator-activated receptor gamma (PPAR- $\gamma$ ), the fat mass and obesity-associated (FTO), and the melanocortin-4 receptor (MC4R) genes. Aging 2018; 10(1): 72-82.

44. Chambers JC, Elliott P, Zabaneh D, Zhang W, Li Y, Froguel P, et al. Common genetic variation near MC4R is associated with waist circumference and insulin resistance. Nature Genetics 2008; 40: 716-718.

45. Sovio U, Mook-Kanamori DO, Warrington NM, Lawrence R, Briollais L, Palmer CNA, et al. Association between Common Variation at the FTO Locus and Changes in Body Mass Index from Infancy to Late Childhood: The Complex Nature of Genetic Association through Growth and Development. PLoS One, 2011.

46. Fernandes AE, Melo ME, Fujiwara CTH, Pioltine MB, Matioli SR, Santos A, et al. Associations between a common variant near the MC4R gene and serum triglyceride levels in an obese pediatric cohort. Endocrine 2015; 49: 653-658.

481

482

48. Dudbridge F, Pashayan N, Yang J. Predictive accuracy of combined genetic and environmental

47. Smith JA, Ware EB, Middha P, Beacher L, Kardia SLR. Current Applications of Genetic Risk Scores to Cardiovascular Outcomes and Subclinical Phenotypes. Curr Epidemiol Rep 2015; 2: $180-190$.

50. Dron JS, Hegele RA. The evolution of genetic-based risk scores for lipids and cardiovascular risk scores. Genet Epidemiol 2017; 42: 4-19.

49. Pereira A, Mendonça MI, Borges S, Souza AC, Freitas S, Henriques E, et al. Additional value of a combined genetic risk score to standard cardiovascular stratification. Genet Mol Bio, 41, 4, 766774 (2018).

disease. Curr Opin Lipidol 2019; 30(2): 71-81.

51. Daya M, Pujianto DA, Witjaksono F, Priliani L, Susanto J, Lukito W, et al. Obesity risk and preference for high dietary fat intake are determined by FTO rs9939609 gene polymorphism in selected Indonesian adults. Asia Pac J Clin Nutr 2019; 28(1):183-191. 
52. Pettermann F, Villagran M, Troncoso C, Mardones L, Leiva AN, Martínez MA, et al. Asociación entre el polimorfismo rs9939609 del gen FTO y marcadores de adiposidad em población adulta chilena. Rev Med Chil 2018; 146: 717 - 726.

53. Almeida SM, Furtado JM, Mascarenhas P, Ferraz ME, Ferreira JC, Monteiro MP, et al. Association between LEPR, FTO, MC4R, and PPARG-2 polymorphisms with obesity traits and metabolic phenotypes in school-aged children. Endocrine (2018) 60:466-478.

54. Sharifi S, Daghighi S, Motazacker MM, Badlou B, Sanjabi B, Akbarkhanzadeh A, et al. Superparamagnetic iron oxide nanoparticles alter expression of obesity and T2D-associated risk genes in human adipocytes. Scientific Reports 2013.

\section{Funding statement}

Our study was supported by Fundação de Amparo à Pesquisa do Estado de Minas Gerais (FAPEMIG - CDS-APQ-02979-16 and 02055-13), Conselho Nacional de Desenvolvimento Científico e Tecnológico (CNPq - 478910/2013-4, 407547/2012-6 and 485124/2011-4), and the Coordenação de Aperfeiçoamento de Pessoal de Nivel Superior (CAPES - code 001). The CNPq, FAPEMIG, and CAPES had no role in the design, analysis or writing of this article.

\section{Conflict of interest statement}

The authors declare no conflicts of interest.

\section{Authorship}

M.A.S assisted the conception and design of this work, analysis and interpretation of the data, conducted the literature search, as well as wrote the manuscript. C.M.M.R. assisted the conception and design of this work, revised and approved the final version to be published. M.B.L. assisted data collection, revised and approved the final version to be published. S.A.V.R. revised and approved the final version to be published. S.C.C.F. assisted data collection, revised and approved the final version to be published. S.C.C.F. revised and approved the final version to be published. J.G.V.N designed the study including the data collection, coordinated, supervised and approved the final version to be published. J.I.A.L designed the study including the data collection, coordinated, supervised and approved the final version to be published. D.F.D designed the study including the data collection, coordinated, supervised and approved the final version to be published. J.F.N designed the study including the data collection, coordinated, supervised and approved the final version to be published.

\section{Ethics approval}

This study was developed according to the guidelines established in the Declaration of Helsinki and approved by the Human Research Ethics Committee of the Federal University of Viçosa (UFV, in Portuguese) (protocols numbers 663.171/2014, 892476/2014 and 2.832.590/2018).). All parents and 
535 children were informed about the study's purpose and all guardians of the children signed the Informed 536 Consent Form. 
Table 1. Distribution of lipid markers and, atherogenic indexes according to sociodemographic, anthropometric, body composition and lifestyle characteristics in children from Viçosa, Minas Gerais, Brazil, 2015.

\begin{tabular}{|c|c|c|c|c|c|c|c|c|c|c|c|}
\hline \multirow[t]{2}{*}{ Characteristics } & \multirow[t]{2}{*}{$\mathrm{N}$} & \multicolumn{2}{|c|}{ Total cholesterol (mg/dL) } & \multicolumn{2}{|c|}{ HDL-c (mg/dL) } & \multicolumn{2}{|c|}{ LDL-c (mg/dL) } & \multicolumn{2}{|c|}{ Triglyceride (mg/dL) } & \multicolumn{2}{|c|}{ Non-HDL-c (mg/dL) } \\
\hline & & Mean \pm SD & $P$ value & Mean \pm SD & $P$ value & Mean $\pm \mathrm{SD}$ & $P$ value & Mean \pm SD & $P$ value & Mean \pm SD & $P$ value \\
\hline \multicolumn{12}{|l|}{ Sex } \\
\hline Female & 265 & $157.82 \pm 27.08$ & 0.37 & $49.74 \pm 10.26$ & 0.55 & $91.11 \pm 24.06$ & 0.23 & $70.56 \pm 28.94$ & 0.09 & $107.69 \pm 25.23$ & 0.22 \\
\hline Male & 279 & $155.73 \pm 27.30$ & & $50.28 \pm 10.94$ & & $93.59 \pm 23.66$ & & $75.21 \pm 34.18$ & & $105.45 \pm 25.00$ & \\
\hline \multicolumn{12}{|l|}{ Height-for-age (Z-score) } \\
\hline-1 to $<0$ & 186 & $157.80 \pm 26.28$ & 0.28 & $49.47 \pm 10.48$ & 0.63 & $94.13 \pm 22.51$ & $0.02 *$ & $70.05 \pm 27.83$ & 0.08 & $107.75 \pm 24.69$ & 0.05 \\
\hline 0 to 1 & 206 & $157.50 \pm 29.12$ & & $50.34 \pm 10.48$ & & $93.09 \pm 25.77$ & & $71.48 \pm 32.17$ & & $107.16 \pm 26.97$ & \\
\hline$>1$ & 152 & $154.65 \pm 25.55$ & & $50.20 \pm 10.92$ & & $89.29 \pm 22.55$ & & $78.44 \pm 35.14$ & & $104.44 \pm 23.00$ & \\
\hline \multicolumn{12}{|l|}{ BMI-for-age (Z-score) } \\
\hline$<-2$ & 81 & $156.34 \pm 32.10$ & 0.38 & $48.34 \pm 9.75$ & $0.01 *$ & $95.97 \pm 29.27$ & 0.74 & $69.60 \pm 27.94$ & $<0.0001^{*}$ & $108.00 \pm 30.11$ & 0.63 \\
\hline-2 to 1 & 306 & $157.72 \pm 26.30$ & & $51.30 \pm 10.96$ & & $91.87 \pm 22.66$ & & $67.87 \pm 25.73$ & & $106.07 \pm 23.78$ & \\
\hline 1 to 2 & 97 & $157.31 \pm 25.32$ & & $49.78 \pm 10.57$ & & $92.90 \pm 23.16$ & & $79.37 \pm 37.96$ & & $107.53 \pm 24.53$ & \\
\hline$>2$ & 60 & $151.93 \pm 27.46$ & & $46.00 \pm 8.47$ & & $89.28 \pm 22.71$ & & $92.85 \pm 43.00$ & & $105.93 \pm 25.91$ & \\
\hline \multicolumn{12}{|l|}{$\%$ Body fat (terciles) } \\
\hline$\leq 15.7$ & 178 & $153.65 \pm 27.93$ & 0.89 & $49.48 \pm 10.35$ & $0.04 *$ & $90.86 \pm 25.72$ & 0.81 & $67.28 \pm 26.84$ & $<0.0001^{*}$ & $104.17 \pm 25.86$ & 0.52 \\
\hline 15.7 to 24.4 & 175 & $158.95 \pm 27.24$ & & $51.78 \pm 10.81$ & & $93.19 \pm 23.76$ & & $67.62 \pm 25.30$ & & $107.16 \pm 24.31$ & \\
\hline$>24.4$ & 191 & $157.78 \pm 26.28$ & & $48.85 \pm 10.44$ & & $93.05 \pm 22.11$ & & $83.14 \pm 38.37$ & & $108.35 \pm 25.12$ & \\
\hline \multicolumn{12}{|l|}{ Screen time (hours/day) ${ }^{1}$} \\
\hline$\leq 2$ & 241 & $155.36 \pm 25.38$ & 0.07 & $49.37 \pm 9.74$ & 0.26 & $91.60 \pm 23.12$ & 0.12 & $72.55 \pm 33.12$ & 0.75 & $105.54 \pm 24.27$ & 0.14 \\
\hline$>2$ & 303 & $157.95 \pm 28.5$ & & $50.50 \pm 11.21$ & & $93.00 \pm 24.43$ & & $73.25 \pm 30.74$ & & $107.44 \pm 25.79$ & \\
\hline \multicolumn{12}{|l|}{ Per capita income (US\$) $)^{\dagger}$} \\
\hline$<90.1\left(1^{\circ}\right.$ tercile $)$ & 182 & $157.33 \pm 25.19$ & 0.09 & $49.33 \pm 11.12$ & 0.38 & $92.69 \pm 21.94$ & $0.02 *$ & $67.74 \pm 30.60$ & $0.004^{*}$ & $108.00 \pm 23.13$ & 0.11 \\
\hline 90.1 to 157.8 ( $2^{\circ}$ tercile $)$ & 181 & $154.88 \pm 27.11$ & & $49.29 \pm 9.93$ & & $90.57 \pm 25.37$ & & $75.13 \pm 33.24$ & & $105.59 \pm 25.66$ & \\
\hline$>157.8\left(3^{\circ}\right.$ tercile $)$ & 181 & $158.29 \pm 28.98$ & & $51.35 \pm 10.67$ & & $93.94 \pm 23.93$ & & $75.45 \pm 30.92$ & & $106.36 \pm 26.37$ & \\
\hline \multicolumn{12}{|l|}{ Maternal education (years) } \\
\hline$\leq 4$ & 66 & $153.75 \pm 24.36$ & $0.01 *$ & $50.37 \pm 9.60$ & 0.96 & $86.20 \pm 20.85$ & $<0.0001 *$ & $69.83 \pm 31.29$ & $0.02 *$ & $103.37 \pm 20.98$ & $<0.0001 *$ \\
\hline 5 to 10 & 168 & $153.10 \pm 25.59$ & & $49.51 \pm 10.10$ & & $88.81 \pm 23.04$ & & $71.32 \pm 34.88$ & & $103.58 \pm 24.21$ & \\
\hline 11 & 210 & $157.89 \pm 28.33$ & & $49.86 \pm 11.63$ & & $94.66 \pm 24.28$ & & $72.40 \pm 28.65$ & & $108.02 \pm 25.12$ & \\
\hline$\geq 12$ & 98 & $163.14 \pm 28.07$ & & $50.78 \pm 9.50$ & & $98.02 \pm 24.77$ & & $79.67 \pm 32.56$ & & $111.21 \pm 28.51$ & \\
\hline
\end{tabular}


Continuation.

\begin{tabular}{|c|c|c|c|c|c|c|c|c|c|c|c|}
\hline \multirow[t]{2}{*}{ Characteristics } & \multirow[t]{2}{*}{$\mathrm{N}$} & \multicolumn{2}{|c|}{ TC/HDL-c } & \multicolumn{2}{|c|}{ LDL-c/HDL-c } & \multicolumn{2}{|c|}{$\mathrm{AC}$} & \multicolumn{2}{|l|}{ LCI } & \multicolumn{2}{|c|}{ AIP } \\
\hline & & Mean \pm SD & $P$ value & Mean \pm SD & $P$ value & $\begin{array}{c}\text { Mean } \pm \\
\text { SD }\end{array}$ & $P$ value & Mean \pm SD & $P$ value & Mean \pm SD & $P$ value \\
\hline \multicolumn{12}{|l|}{ Sex } \\
\hline Female & 265 & $3.5 \pm 0.68$ & 0.29 & $1.89 \pm 0.62$ & 0.27 & $2.25 \pm 0.68$ & 0.29 & $25.01 \pm 17.59$ & 0.10 & $0.15 \pm 0.21$ & 0.15 \\
\hline Male & 279 & $3.19 \pm 0.70$ & & $1.95 \pm 0.61$ & & $2.19 \pm 0.70$ & & $22.37 \pm 17.59$ & & $0.12 \pm 0.21$ & \\
\hline \multicolumn{12}{|l|}{ Height-for-age (Z-score) } \\
\hline-1 to $<0$ & 186 & $3.28 \pm 0.70$ & 0.06 & $1.97 \pm 0.60$ & $0.02 *$ & $2.28 \pm 0.70$ & 0.06 & $23.28 \pm 16.74$ & 0.54 & $0.12 \pm 0.21$ & 0.23 \\
\hline 0 to 1 & 206 & $3.21 \pm 0.72$ & & $1.92 \pm 0.65$ & & $2.21 \pm 0.72$ & & $23.98 \pm 21.22$ & & $0.12 \pm 0.20$ & \\
\hline$>1$ & 152 & $3.16 \pm 0.64$ & & $1.85 \pm 0.58$ & & $2.16 \pm 0.64$ & & $23.92 \pm 18.01$ & & $0.16 \pm 0.22$ & \\
\hline \multicolumn{12}{|l|}{ BMI-for-age (Z-score) } \\
\hline$<-2$ & 81 & $3.31 \pm 0.77$ & $0.02 *$ & $2.05 \pm 0.71$ & 0.13 & $2.31 \pm 0.77$ & $0.02 *$ & $24.81 \pm 22.64$ & $0.002 *$ & $0.13 \pm 0.20$ & $<0.0001 *$ \\
\hline-2 to 1 & 306 & $3.16 \pm 0.67$ & & $1.86 \pm 0.59$ & & $2.21 \pm 0.67$ & & $21.28 \pm 14.90$ & & $0.10 \pm 0.20$ & \\
\hline$>1$ to 2 & 97 & $3.25 \pm 0.67$ & & $1.94 \pm 0.59$ & & $2.25 \pm 0.67$ & & $26.33 \pm 22.43$ & & $0.17 \pm 0.21$ & \\
\hline$>2$ & 60 & $3.37 \pm 0.68$ & & $2.00 \pm 0.61$ & & $2.37 \pm 0.68$ & & $30.49 \pm 22.84$ & & $0.26 \pm 0.22$ & \\
\hline \multicolumn{12}{|l|}{$\%$ Body fat (terciles) } \\
\hline$\leq 15.7$ & 178 & $3.20 \pm 0.75$ & 0.11 & $1.91 \pm 0.68$ & 0.37 & $2.20 \pm 0.75$ & 0.11 & $21.58 \pm 19.36$ & $0.001 *$ & $0.11 \pm 0.20$ & $<0.0001 *$ \\
\hline 15.7 to 24.4 & 175 & $3.15 \pm 0.63$ & & $1.86 \pm 0.57$ & & $2.15 \pm 0.63$ & & $21.38 \pm 14.10$ & & $0.09 \pm 0.19$ & \\
\hline$>24.4$ & 191 & $3.31 \pm 0.67$ & & $1.97 \pm 0.58$ & & $2.31 \pm 0.67$ & & $27.89 \pm 21.44$ & & $0.20 \pm 0.22$ & \\
\hline \multicolumn{12}{|l|}{ Screen time (hours/day) ${ }^{1}$} \\
\hline$\leq 2$ & 241 & $3.22 \pm 0.67$ & 0.83 & $1.92 \pm 0.60$ & 0.80 & $2.22 \pm 0.67$ & 0.83 & $23.18 \pm 18.14$ & 0.37 & $0.13 \pm 0.21$ & 0.98 \\
\hline$>2$ & 303 & $3.22 \pm 0.71$ & & $1.91 \pm 0.63$ & & $2.22 \pm 0.71$ & & $24.16 \pm 19.44$ & & $0.13 \pm 0.22$ & \\
\hline \multicolumn{12}{|l|}{ Per capita income (US\$) ${ }^{\dagger}$} \\
\hline$<90.1\left(1^{\circ}\right.$ tercile $)$ & 182 & $3.30 \pm 0.75$ & 0.82 & $1.97 \pm 0.66$ & 0.35 & $2.30 \pm 0.75$ & 0.82 & $22.75 \pm 19.73$ & $0.03 *$ & $0.11 \pm 0.21$ & $0.01 *$ \\
\hline 90.1 to $157.8\left(2^{\circ}\right.$ tercile $)$ & 181 & $3.22 \pm 0.69$ & & $1.90 \pm 0.62$ & & $2.22 \pm 0.69$ & & $23.84 \pm 19.23$ & & $0.15 \pm 0.20$ & \\
\hline$>157.8\left(3^{\circ}\right.$ tercile $)$ & 181 & $3.15 \pm 0.63$ & & $1.89 \pm 0.57$ & & $2.15 \pm 0.63$ & & $24.49 \pm 17.70$ & & $0.14 \pm 0.21$ & \\
\hline \multicolumn{12}{|l|}{ Maternal education (years) } \\
\hline$\leq 4$ & 66 & $3.11 \pm 0.52$ & $0.01 *$ & $1.75 \pm 0.46$ & $<0.0001 *$ & $2.11 \pm 0.52$ & $0.01 *$ & $19.38 \pm 12.83$ & $0.003 *$ & $0.11 \pm 0.22$ & $0.01 *$ \\
\hline 5 to 10 & 168 & $3.18 \pm 0.69$ & & $1.86 \pm 0.62$ & & $2.18 \pm 0.69$ & & $22.46 \pm 20.90$ & & $0.12 \pm 0.21$ & \\
\hline 11 & 210 & $3.27 \pm 0.72$ & & $1.98 \pm 0.64$ & & $2.27 \pm 0.72$ & & $23.98 \pm 16.79$ & & $0.14 \pm 0.21$ & \\
\hline$\geq 12$ & 98 & $3.29 \pm 0.71$ & & $1.99 \pm 0.64$ & & $2.29 \pm 0.71$ & & $28.59 \pm 21.92$ & & $0.17 \pm 0.19$ & \\
\hline
\end{tabular}

Abbreviations: SD: Standard Deviation; BMI: body mass index; HDL-c: high-density lipoprotein; LDL-c: low-density lipoprotein; TC: Total cholesterol; AC:

atherosclerosis coefficient; LCI: lipoprotein combined index; AIP: atherogenic index of plasma.

Linear regression models with lipid markers and, atherogenic indexes as the continuous outcome. For variables with three or more categories, $\mathrm{P}$ -

value was from Wald test for linear trend representing ordinal categories as continuous. Robust variance estimations were specified in all models.

${ }^{\dagger}$ Approximate exchange rates of real (R\$) to dollar (US\$) at the time of this study (US\$1.00 = R \$ 3.33). $* P<0.05$ 
Table 2. Association of the risk allele of the FTO rs9939609 with the lipid markers and atherogenic indexes in children from Viçosa, Minas Gerais, Brazil, 2015.

\begin{tabular}{lcccccc}
\hline \multirow{2}{*}{ Markers } & \multicolumn{3}{c}{ Unadjusted difference $(95 \% \mathrm{CI})^{1}$} & \multicolumn{3}{c}{ Adjusted difference $(95 \% \mathrm{CI})^{2}$} \\
\cline { 2 - 6 } & TT & FTO gene & AT/AA & $P$ value & TT & ATO gene \\
\hline Total cholesterol (mg/dL) & Reference & $0.75(-4.02,5.53)$ & 0.76 & Reference & $0.04(-4.76,4.85)$ & 0.99 \\
Triglyceride (mg/dL) & Reference & $-4.14(-10.35,2.07)$ & 0.19 & Reference & $-3.32(-9.19,2.54)$ & 0.27 \\
HDL-c (mg/dL) & Reference & $-0.64(-2.56,1.28)$ & 0.51 & Reference & $-1.01(-2.94,0.91)$ & 0.30 \\
LDL-c (mg/dL) & Reference & $1.29(-2.81,5.40)$ & 0.54 & Reference & $0.90(-3.19,5.01)$ & 0.66 \\
Non-HDL-c (mg/dL) & Reference & $1.09(-3.25,5.45)$ & 0.62 & Reference & $0.65(-3.73,5.04)$ & 0.77 \\
TC/HDL-c & Reference & $0.05(-0.06,0.18)$ & 0.35 & Reference & $0.06(-0.05,0.18)$ & 0.27 \\
LDL-c/HDL-c & Reference & $0.05(-0.05,0.16)$ & 0.35 & Reference & $0.05(-0.05,0.16)$ & 0.29 \\
AC & Reference & $0.05(-0.06,0.18)$ & 0.34 & Reference & $0.06(-0.05,0.19)$ & 0.27 \\
LCI & Reference & $-0.23(-3.69,3.21)$ & 0.89 & Reference & $0.15(-3.12,3.42)$ & 0.93 \\
AIP & Reference & $0.00(-0.05,0.03)$ & 0.63 & Reference & $0.00(-0.04,0.03)$ & 0.95
\end{tabular}

Abbreviations: 95\%CI: 95\% Confidence Interval; HDL-c: high-density lipoprotein; LDL-c: low-density lipoprotein; TG: Triglyceride; AC:

atherosclerosis coefficient; LCI: lipoprotein combined index; AIP: atherogenic index of plasma; TT: individuals without polymorphism; AT:

heterozygous individuals with a risk allele; AA: individuals with polymorphism in the FTO gene.

${ }^{1}$ From linear regression models with each lipid marker as a continuous outcome and FTO gene categories as predictor. Robust estimates of variance were specified in all models.

${ }^{2}$ From linear regression adjusted for sex, age, screen time, per capita income, maternal education, total energy intake and $\%$ body fat. 
Table 3. Association of the risk allele of the MC4R rs17782313 with the lipid markers and atherogenic indexes in children from Viçosa, Minas Gerais, Brazil, 2015.

\begin{tabular}{lcccccc}
\hline \multirow{2}{*}{ Markers } & \multicolumn{3}{c}{ Unadjusted difference $(95 \% \mathrm{CI})^{1}$} & \multicolumn{3}{c}{${\text { Adjusted difference }(95 \% \mathrm{CI})^{2}}^{2}$} \\
\cline { 2 - 7 } & TT & TC4R gene & & MC4R gene & TC/CC & $P$ value \\
\hline Total cholesterol (mg/dL) & Reference & $0.51(-4.09,5.11)$ & 0.83 & Reference & $1.68(-3.11,6.48)$ & 0.49 \\
Triglyceride (mg/dL) & Reference & $-0.32(-5.96,5.32)$ & 0.91 & Reference & $0.57(-5.08,6.23)$ & 0.84 \\
HDL-c (mg/dL) & Reference & $0.89(-1.01,2.79)$ & 0.36 & Reference & $0.83(-1.10,2.77)$ & 0.40 \\
LDL-c (mg/dL) & Reference & $-1.37(-5.42,2.67)$ & 0.51 & Reference & $0.03(-4.09,4.17)$ & 0.99 \\
Non-HDL-c (mg/dL) & Reference & $-0.05(-4.36,4.24)$ & 0.98 & Reference & $1.05(-3.44,5.55)$ & 0.65 \\
TC/HDL-c & Reference & $0.00(-0.12,0.12)$ & 0.99 & Reference & $0.02(-0.10,0.16)$ & 0.67 \\
LDL-c/HDL-c & Reference & $-0.02(-0.13,0.08)$ & 0.70 & Reference & $0.01(-0.10,0.12)$ & 0.85 \\
AC & Reference & $0.00(-0.12,0.12)$ & 0.99 & Reference & $0.02(-0.10,0.16)$ & 0.67 \\
LCI & Reference & $0.53(-2.88,3.95)$ & 0.76 & Reference & $1.56(-2.12,5.25)$ & 0.41 \\
AIP & Reference & $-0.01(-0.04,0.02)$ & 0.66 & Reference & $0.00(-0.04,0.03)$ & 0.78
\end{tabular}

Abbreviations: 95\%CI: 95\% Confidence Interval; HDL-c: high-density lipoprotein; LDL-c: low-density lipoprotein; TG: Triglyceride; AC: atherosclerosis coefficient; LCI: lipoprotein combined index; AIP: atherogenic index of plasma, TT: individuals without polymorphism; TC: heterozygous individuals with a risk allele; CC: individuals with polymorphism in the $M C 4 R$ gene.

${ }^{1}$ From linear regression models with each lipid marker as a continuous outcome and $M C 4 R$ gene categories as predictor. Robust estimates of variance were specified in all models.

${ }^{2}$ From linear regression adjusted for sex, age, screen time, per capita income, maternal education, total energy intake and \% body fat. 
Table 4. Association of the risk allele of the MTMR9 rs2293855 with the lipid markers and atherogenic indexes in children from Viçosa, Minas Gerais, Brazil, 2015.

\begin{tabular}{|c|c|c|c|c|c|c|}
\hline \multirow{3}{*}{ Markers } & \multicolumn{3}{|c|}{ Unadjusted difference $(95 \% \mathrm{CI})^{1}$} & \multicolumn{3}{|c|}{ Adjusted difference $(95 \% \mathrm{CI})^{2}$} \\
\hline & \multicolumn{3}{|c|}{ MTMR9 gene } & \multicolumn{3}{|c|}{ MTMR9 gene } \\
\hline & GG & AG/AA & $P$ value & GG & $\mathrm{AG} / \mathrm{AA}$ & $P$ value \\
\hline Total cholesterol $(\mathrm{mg} / \mathrm{dL})$ & Reference & $1.21(-3.63,6.05)$ & 0.62 & Reference & $1.33(3.60,6.27)$ & 0.60 \\
\hline Triglyceride $(\mathrm{mg} / \mathrm{dL})$ & Reference & $1.57(-3.68,6.83)$ & 0.56 & Reference & $2.53(-2.72,7.80)$ & 0.34 \\
\hline HDL-c $(\mathrm{mg} / \mathrm{dL})$ & Reference & $-1.41(-2.74,-0.08)$ & $0.04 *$ & Reference & $-1.75(-3.12,-0.38)$ & $0.01 *$ \\
\hline LDL-c $(\mathrm{mg} / \mathrm{dL})$ & Reference & $2.40(-2.04,6.85)$ & 0.29 & Reference & $2.76(-1.69,7.22)$ & 0.22 \\
\hline Non-HDL-c (mg/dL) & Reference & $2.74(-2.13,7.62)$ & 0.27 & Reference & $3.12(-1.77,8.02)$ & 0.21 \\
\hline TC/HDL-c & Reference & $0.12(-0.01,0.26)$ & 0.08 & Reference & $0.15(0.01,0.29)$ & $0.03 *$ \\
\hline LDL-c/HDL-c & Reference & $0.11(-0.01,0.23)$ & 0.08 & Reference & $0.13(0.01,0.25)$ & $0.03^{*}$ \\
\hline $\mathrm{AC}$ & Reference & $0.12(-0.01,0.26)$ & 0.08 & Reference & $0.15(0.01,0.29)$ & $0.03 *$ \\
\hline LCI & Reference & $3.60(-0.66,7.87)$ & 0.10 & Reference & $4.21(-0.01,8.57)$ & 0.05 \\
\hline AIP & Reference & $0.02(-0.01,0.05)$ & 0.19 & Reference & $0.02(-0.01,0.05)$ & 0.10 \\
\hline
\end{tabular}

Abbreviations: 95\%CI: 95\% Confidence Interval; HDL-c: high-density lipoprotein; LDL-c: low-density lipoprotein; TG: Triglyceride; AC:

atherosclerosis coefficient; LCI: lipoprotein combined index; AIP: atherogenic index of plasma; GG: individuals without polymorphism; AG:

heterozygous individuals with a risk allele; AA: individuals with polymorphism in the MTMR9 gene.

${ }^{1}$ From linear regression models with each lipid marker as a continuous outcome and MTMR9 gene categories as predictor. Robust estimates of variance were specified in all models.

${ }^{2}$ From linear regression adjusted for sex, age, screen time, per capita income, maternal education, total energy intake and $\%$ body fat.

$* P$ value $<0.05$ 
Table 5. Association of the risk allele of the genetic risk score with the lipid markers and atherogenic indexes in children from Viçosa, Minas Gerais, Brazil, 2015.

\begin{tabular}{|c|c|c|c|c|c|c|}
\hline \multirow{3}{*}{ Markers } & \multicolumn{3}{|c|}{ Unadjusted difference $(95 \% \mathrm{CI})^{1}$} & \multicolumn{3}{|c|}{ Adjusted difference $(95 \% \mathrm{CI})^{2}$} \\
\hline & \multicolumn{3}{|c|}{ Genetic risk score } & \multicolumn{3}{|c|}{ Genetic risk score } \\
\hline & 0 & $\geq 1$ & $P$ value & 0 & $\geq 1$ & $P$ value \\
\hline Total cholesterol (mg/dL) & Reference & $-0.90(-6.25,4.44)$ & 0.74 & Reference & $-0.07(-5.42,5.26)$ & 0.98 \\
\hline Triglyceride (mg/dL) & Reference & $3.18(-2.99,9.36)$ & 0.31 & Reference & $4.50(-1.50,10.52)$ & 0.14 \\
\hline HDL-c (mg/dL) & Reference & $-2.10(-4.06,-0.14)$ & $0.04 *$ & Reference & $-2.11(-4.08,-0.14)$ & $0.04 *$ \\
\hline LDL-c (mg/dL) & Reference & $-0.45(-5.23,4.31)$ & 0.85 & Reference & $0.29(-4.33,4.92)$ & 0.90 \\
\hline Non-HDL-c (mg/dL) & Reference & $1.47(-3.67,6.62)$ & 0.58 & Reference & $2.20(-2.85,7.27)$ & 0.39 \\
\hline TC/HDL-c & Reference & $0.15(0.001,0.29)$ & $0.04 *$ & Reference & $0.16(0.02,0.31)$ & $0.02 *$ \\
\hline LDL-c/HDL-c & Reference & $0.09(-0.03,0.23)$ & 0.13 & Reference & $0.11(-0.01,0.24)$ & 0.07 \\
\hline $\mathrm{AC}$ & Reference & $0.15(0.002,0.29)$ & $0.04 *$ & Reference & $0.16(0.02,0.31)$ & $0.02 *$ \\
\hline LCI & Reference & $3.61(-0.43,7.65)$ & 0.08 & Reference & $4.36(0.3,8.36)$ & $0.03 *$ \\
\hline AIP & Reference & $0.03(0.00,0.07)$ & 0.07 & Reference & $0.04(0.004,0.08)$ & $0.03^{*}$ \\
\hline
\end{tabular}

Abbreviations: 95\%CI: 95\% Confidence Interval; HDL-c: high-density lipoprotein; LDL-c: low-density lipoprotein; TG: Triglyceride; AC:

atherosclerosis coefficient; LCI: lipoprotein combined index; AIP: atherogenic index of plasma.

${ }^{1}$ From linear regression models with each lipid marker as a continuous outcome and genetic score categories as predictor. Robust estimates of variance were specified in all models.

${ }^{2}$ From linear regression adjusted for sex, age, screen time, per capita income, maternal education, total energy intake and \% body fat.

$* P$ value $<0.05$ 